\title{
O ENSINO DE FILOSOFIA: DESAFIOS E NOVAS PERSPECTIVAS
}

\author{
Renivaldo Santos de Souza ${ }^{1,}$ Odair Benedito Francisco ${ }^{2}$ \\ ${ }^{1}$ Faculdades EST, Mestrado em Teologia, São Leopoldo, RS. ${ }^{2}$ Universidade do Oeste Paulista - UNOESTE, Tutor em \\ Cursos de Pós Graduação, Universidade Estadual Paulista - UNESP, Mestrado em Educação E-mail: \\ rennysousa@hotmail.com.
}

\section{RESUMO}

O Ensino da Filosofia é um desafio para os professores, pois, nem sempre existe uma situação propícia para que a atividade se torne o filosofar. Os desafios do Ensino de Filosofia na Educação Básica é analisar se há ou não no processo de ensino a utilização de métodos adequados ao recomendado pela Base Nacional Comum Curricular, na concepção dos objetivos de aprendizagem como forma de interação social. Os resultados propõem-se a fornecer uma base para os professores que pretendam se valer desses objetivos nas aulas. Entendemos que os resultados serão satisfatórios para a compreensão da Filosofia.

Palavras-chave: Ensino, Filosofia, desafios, estudantes e Base Nacional.

\section{THE PHILOSOPHY OF EDUCATION: CHALLENGES AND NEW PERSPECTIVES}

\begin{abstract}
The philosophy of education is a challenge for teachers, because there is not always a favorable situation for the activity becomes philosophizing. The challenges of Philosophy of Education in Basic Education is to analyze whether or not the teaching process using appropriate methods recommended by the Common National Base Curriculum in the design of the learning objectives as a form of social interaction. The results are proposed to provide a basis for teachers who wish to avail of these objectives in class. We understand that the results will be satisfactory to understanding the philosophy.

Keywords: Education, Philosophy, challenges, students and National Base.
\end{abstract}




\section{INTRODUÇÃO}

O ensino de filosofia nas escolas constitui-se um grande desafio diante das perspectivas contemporâneas, como nos relata acima Freire (1996) que precisa haver motivação para a pesquisa, para a busca, mas na maioria das vezes, apresenta-se como reprodutivo, no sentido de ser apenas aquele em que se estabelece a cronologia, a história de alguns dos pensadores ou filósofos. Nesse sentido, ainda é possível encontrar educador que privilegia filósofos, cujo estudo é mais simples, excluindo temas mais complexos. Há educador que ensina a filosofia apenas de maneira explicativa, descartando a aproximação dos temas explicitados em sala com a realidade, as discussões transversais e inerentes à vida.

Primeiramente, o educador deve pensar em ensinar, além, do conteúdo em sala, como nos relata Freire (1996, p. 141), o ensinar a filosofar, o ler e o pensar para "a construção da consciência coletiva para a formação cidadã e humanizadora". Nessa perspectiva, o Ensino de Filosofia deveria ser obrigatório desde os primeiros anos da Educação Básica e não apenas no Ensino Médio como atualmente está preconizado na Lei de Diretrizes-LDBEN (BRASIL, 1996) e na Base Nacional Comum Curricular-BNCC (BRASIL, 2015), constituindo-se em momentos de aprendizagem, autonomia e habilidade na construção do pensamento, resultados da interação social.

No Ensino de Filosofia, é preciso respeitar as transformações no uso do método e novas maneiras de ensinar, respeitando as formas de comunicação e a possibilidade de aprofundamento. É preciso que o educador "[...] se convença definitivamente de que ensinar não é transferir conhecimento, mas criar as possibilidades para a sua produção ou a sua construção" (FREIRE, 1996, p. 22). A evidência da própria existência - o "penso, logo existo" - traz uma primeira certeza. A razão seria a única coisa verdadeira para alcançar o conhecimento. Descartes (1968 apud SILVA, 1978, p. 184) afirma que "Eu sou uma coisa que pensa, e só do meu pensamento posso ter certeza ou intuição imediata".

Diante disso, objetivou-se com esta pesquisa sobre o Ensino de Filosofia na Educação Básica constatar se há ou não no processo de ensino e aprendizagem a utilização de métodos adequados ao recomendado pela BNCC (BRASIL, 2015), que adota a concepção de objetivos de aprendizagem como forma de interação social e construção do conhecimento a partir das vivências dos estudantes, para a promoção a apropriação do questionamento e dos discursos filosóficos.

\section{METODOLOGIA}

Nesse contexto, analisamos e observamos o documento-base que servirá para nortear todos os projetos pedagógicos, os livros didáticos e programas educacionais do país a partir de 2017: a Base Nacional Comum Curricular (BRASIL, 2015), especificamente ao Ensino de Filosofia, no que tange às propostas de objetivos de aprendizagem e na produção de material.

Quanto à análise documental, como método de investigação, Hegel (1991) afirma que as noções são conjuntivas e não disjuntivas: quem aprende filosofia aprende também a filosofar. Também considera que a filosofia é objeto de uma aprendizagem. Aprender um conteúdo não é incutir algo na mente do estudante para apreendê-lo num processo pedagógico particular. Aprender filosofia é aprender a pensar o divino, a própria constituição do pensamento.

Portanto, a pesquisa bibliográfica de cunho qualitativo priorizou os escritos de autores renomados que tratam sobre a questão do Ensino de Filosofia na escola e na BNCC (BRASIL, 2015).

\section{ANÁLISE DOS RESULTADOS}

No cotidiano escolar, o Ensino de Filosofia acontece pela utilização e produção textual como um fim e não como um meio de participação social, cuja finalidade é inserir o estudante nas práticas sociais presentes no meio em que ele se encontra. A Filosofia é responsável pelo senso 
crítico do indivíduo, pois, como uma disciplina interrogativa, busca o conhecimento, tirando-o do estado de ignorância, do estágio de alienação intelectual.

Neste aspecto, a Filosofia contribui para realização da essência do ser humano: o pensamento. Pode-se evidenciar que há elementos racionais e sociais na construção da consciência de cada indivíduo. Desta forma, a Base Nacional Comum Curricular (BRASIL, 2015), prevista na Constituição Federal (BRASIL, 1988) para a Educação Básica, introduz os objetivos de aprendizagem para Ensino de Filosofia nas escolas brasileiras. Segundo esse documento, surgem os objetivos de aprendizagem no Ensino de Filosofia para que o estudante possa pensar de forma filosófica, de forma interdisciplinar os conhecimentos anteriores e atuais na linguagem oral ou escrita.

Portanto, os objetivos favorecem ao estudante as condições para discutir os problemas sociais, históricos em qualquer civilização e, correlacionando-os com as questões contemporâneas. Assim, os professores devem desenvolver métodos que garantam as condições de relacionar o ensino e a vida para enfrentar os problemas pessoais, sociais com as abordagens filosóficas (BRASIL, 2015).

Em relação à filosofia sistemática produzida na universidade, é marcada por uma crítica nietzschiana da exacerbação do racionalismo na modernidade, por uma afirmação da vida e da criação. Sobre isso, Nietzsche (1983) nos adverte para a morte da Filosofia, pois, quando recorremos à exposição formal e erudita da história dos pensamentos, não educamos para a sabedoria, nada mais fazemos do que preparar o estudante para provas. Por isso mesmo, em função desse estranho ao filosofar, a Filosofia é motivo de escárnio e de desprezo entre os estudantes.

Como resultado nesse processo, a Filosofia contribui para a formação da consciência crítica do estudante. É da própria filosofia a preocupação em criticar-se a si mesma, banindo qualquer tipo de preconceito que restrinja ou limite o seu próprio movimento de elaboração conceitual. Assim, não existem propósitos ou demarcações ao filosofar que impeçam qualquer pensador de eleger os temas de sua investigação e os métodos que utilizará. Filosofar é antes de tudo, um exercício de liberdade de pensamento que não aceita ser tutelado por ideologias.

A BNCC garante ao estudante no Ensino de Filosofia os objetivos de aprendizagem, dentre eles, a capacidade lógica e a retórica para o desenvolvimento da argumentação oral ou escrita e dos discursos para entender as dificuldades da sociedade contemporânea (BRASIL, 2015).

Sobre isso, o professor deve desenvolver e propor estratégias para que o estudante analise todos os processos de formação ideológica dominante capitalista e adquira condições filosóficas de opinar com método e precisão cientifica (BRASIL, 2015).

Frente aos desafios contemporâneos lançados à civilização na atual etapa da globalização, que passa por transformações, novamente a Filosofia está sendo desafiada naquilo que é mais fundamental: elaborar conceitos que permitam compreender criticamente o que acontece à nossa volta e no mundo, a fim de que nossas escolhas e ações contribuam para expandir as liberdades públicas e privadas, ao invés de restringi-las e discriminá-las.

\section{DISCUSSÃO}

Notamos um novo patamar na colocação dos problemas, apontando perspectivas de como tratá-los tendo em vista expandir a vida, o mundo e as liberdades humanas. A partir daí destacamos que a Filosofia contribui para a formação da consciência crítica do indivíduo como núcleo central na análise da conexão entre filosofia e cidadania, a investigação sobre as condições do exercício da liberdade como essencial do ser humano. Assim, a Base Nacional sugere novos objetivos para garantir a estudante filosofar sobre a vida e da morte, com condições da vida humana e como enfrentar os diversos, discursivos e não discursivos (BRASIL, 2015). 
Afinal, compreender a importância da Filosofia na formação escolar básica e os possíveis lugares do filosofar na vida. É possível perceber que muitos professores ainda não têm clareza quanto à sua concepção filosófica e o que garante a BNCC, necessitando de apoio na elaboração de propostas para o Ensino de Filosofia. Para Freire (1996), o ser humano é inacabado, foi lançado ao mundo sem o seu consentimento ou querer. Sua existência é determinada pelas contingências da vida, "é o anseio de ser o que não somos, é o anseio de continuar sendo. O homem só pode transcender, se for capaz de projetar-se. Assim ele sempre busca um sentido para sua vida" (MORENTE, 1980, p. 316).

É certo que, ainda há grandes questionamentos acerca da utilização de vários recursos em sala. Sabe-se que o professor deve procurar outros recursos e não exclusivamente ao livro didático, ou seja, dar uma direção às aulas e a vida. Não existem verdades absolutas, a nossa vida é essa abertura ao mundo. "Do existir é próprio, por um lado, a facticidade, por outro, a abertura (...) o estar essencialmente aberto para as coisas" (MARIAS, 2004, p. 480).

Nas propostas da BNCC, os objetivos de aprendizagem procuram verificar se os próprios estudantes podem ser os protagonistas do saber filosófico em sala e fora dela para a orientação e suporte de circulação do texto, se em exposição, se em leitura para a turma, se em jornal escolar e social (BRASIL, 2015).

\section{CONSIDERAÇÕES FINAIS}

O Ensino de Filosofia pode e deve dialogar com todas as áreas do saber de forma interdisciplinar, mantendo-se, todavia, fiel às especificidades que justificam sua inserção no currículo pela BNCC (BRASIL, 2015). Ainda sobre as propostas destaca-se a necessidade de que sejam criadas condições de produção de conhecimentos, ajudando o estudante a produzi-los, considerando toda a diversidade atual. As novas propostas pedagógicas começaram a ser elaboradas em atendimento às exigências da LDBEN (BRASIL, 1996), a BNCC (BRASIL, 2015) que definem os conhecimentos de Filosofia como atributos de várias áreas de conhecimento, alicerçadas na formação ética, política e a cidadania. Para Freire (1996, p. 22) "ensinar não é transferir conhecimento, mas criar as possibilidades para a sua produção ou a sua construção".

Acreditamos que o Ensino de filosofia precisa ter um lugar definido não apenas no ensino médio, mas em toda a Educação Básica, com presença na condição de disciplina, com papel e conteúdos definidos obrigatórios que garantam os direitos e objetivos de aprendizagem para todos os estudantes brasileiros. Não podemos negar o avanço alcançado na elaboração da BNCC (BRASIL, 2015) que deve contemplar todos os critérios estabelecidos para a disciplina que seguem a concepção de linguagem como forma de interação. Mas ainda há um caminho a ser percorrido quanto ao uso efetivo e real do filosofar.

Assim as propostas precisam se preocupar efetivamente com a aprendizagem em si, e aquilo que o estudante realmente quer dizer e precisa aprender sobre a interação real entre ele e as diferentes circunstâncias e em diferentes situações sociais, para as condições reais e efetivas do pensar filosófico.

\section{REFERÊNCIAS}

BRASIL. Base Nacional Comum Curricular. 1. ed. Brasília: MEC/SEB, 2015. Disponível em: http://basenacionalcomum.mec.gov.br/. Acesso em: 10 abr. 2016.

.Lei de Diretrizes e Bases da Educação Nacional. 11. edição. Brasília: MEC/SEF, 1996. Disponível em: http://www.planalto.gov.br/ccivil_03/LEIS/I9394.htm. Acesso em: 26. maio. 2016.

FREIRE, P. Pedagogia da Autonomia: saberes necessários à prática educativa. 36. ed. São Paulo: Paz e Terra, 1996. 
HEGEL, G. W. F. Fenomenologia do Espírito. 2. ed. Trad. Paulo Meneses. Petrópolis: Vozes, 1991.

MARÍAS, J. História da Filosofia. 13. ed. São Paulo: Martins Fontes, 2004.

NIETSZCHE, F. Os pensadores Filosofia. 4. ed. São Paulo: Abril Cultural, 1983. (Pensadores).

MORENTE, M. G. Fundamentos da filosofia: lições preliminares. 8. ed. São Paulo: Mestre Jou, 1980.

SILVA, M. O. da R. O mito cartesiano e outros ensaios. 4. ed. São Paulo: Hucitec, 1978. 